Article

\title{
Association between Rheumatoid Arthritis and Poor Self-Perceived Oral Health in Korean Adults
}

\author{
Hana Shim ${ }^{1}$, Jungwan Koo ${ }^{2, *,+}$ and Joonho Ahn ${ }^{2, *,+}$ (D) \\ 1 Department of Public Health, Graduate School, The Catholic University of Korea, Seoul 06591, Korea; \\ shn0412@naver.com \\ 2 Department of Occupational and Environmental Medicine, Seoul St. Mary's Hospital, College of Medicine, \\ The Catholic University of Korea, Seoul 06591, Korea \\ * Correspondence: jwkoo@catholic.ac.kr (J.K.); drcox@naver.com (J.A.); Tel.: +82-2-2258-6268 (J.K.); \\ +82-2-2258-6701 (J.A.); Fax: +82-2-2258-6678 (J.K. \& J.A.) \\ + These authors contributed equally to this work.
}

Citation: Shim, H.; Koo, J.; Ahn, J Association between Rheumatoid Arthritis and Poor Self-Perceived Oral Health in Korean Adults. Healthcare 2022, 10, 427. https:// doi.org/10.3390/healthcare10030427 Academic Editor: Takahiro Kanno

Received: 6 January 2022

Accepted: 22 February 2022

Published: 24 February 2022

Publisher's Note: MDPI stays neutral with regard to jurisdictional claims in published maps and institutional affiliations.

Copyright: (C) 2022 by the authors. Licensee MDPI, Basel, Switzerland. This article is an open access article distributed under the terms and conditions of the Creative Commons Attribution (CC BY) license (https:// creativecommons.org/licenses/by/ $4.0 /)$.

\begin{abstract}
Background and objective: Rheumatoid arthritis (RA) and oral health problems have been reported as specific disease units; however, this study was conducted to evaluate the association between RA and comprehensive oral health status. Therefore, this study aimed to assess the association between RA and oral health using self-perceived oral health (SPOH) variables that can determine the oral health status in Korean adults using representative national data. Methods: Data from 40,186 selected participants were collected from the Korea National Health and Nutrition Examination Survey (KNHANES) between 2007 and 2018. The prevalence relative risk (PRR) was estimated using Poisson regression analysis to obtain the risk ratio of the $\mathrm{SPOH}$ according to RA. Results: The risk of $\mathrm{SPOH}$ depending on the RA status was statistically significant (odds ratio [OR] $=1.108,95 \%$ confidence interval [CI] 1.005-1.222). In addition, the risk of SPOH depending on the RA status was higher in the group with diabetes mellitus $(\mathrm{DM})(\mathrm{OR}=1.205,95 \% \mathrm{CI} 0.966-1.503)$ than in the group without $\mathrm{DM}$ (OR $=1.088,95 \%$ CI 0.976-1.214). Conclusions: In this study, a significant association was identified between RA and SPOH. Oral health experts should identify the factors affecting the oral health of patients with RA and provide correct oral health care; however, additional research is needed.
\end{abstract}

Keywords: arthritis; rheumatoid; oral health; cross-sectional studies

\section{Introduction}

Health refers to a state of complete physical, mental, and social well-being. Health level is affected by both objective and subjective health status [1]. The objective health of an individual is assessed through clinical tests by medical personnel and can measure physical conditions such as illness or disability. Subjective health of an individual can predict more accurate levels of quality of life [2] and well-being and is considered an indicator of good health that reflects personal views on health that cannot be measured by medical methods [3]. When individuals rate their overall oral condition, it is referred to as self-perceived oral health (SPOH) and it can indicate one's current oral health status. The perceived oral health status is related to health promotion; therefore, objective and subjective oral health must be considered [4].

Oral health is an essential part of an individual's overall health and well-being and an important factor in digestion and nutrition. Improving oral health can affect the overall quality of life of individuals and society [5]. The World Health Organization [6] and World Dental Federation [7] emphasize that oral health is an essential component of overall health and quality of life and define it as a contributing factor to the physical, psychological, and social well-being of people [8].

Rheumatoid arthritis (RA) is a chronic disease that causes systemic inflammation, particularly of the joints, owing to adverse reactions of autoimmunity, and can impair 
daily activities [9]. Previous studies, which observed an association between RA and poor oral health, have shown similar mechanisms in the immune response between RA and periodontal disease (PD) [10]. Patients with PD were at a higher risk of developing RA [11] and patients with RA had fewer teeth [12]. The authors reported that periodontal bacterial DNA is a possible trigger factor for RA [13] and that patients with RA have a higher risk of PD than the general population [14-16]. Recently, the association between oral health-related quality of life and RA [17-19], a study evaluating oral health status and oral care reported by RA patients [20], and research reporting on oral hygiene and the dysfunction of temporomandibular joints (TMJ) in RA patients has been extensively studied [21,22]; however, this is the first study in northeast Asia. No studies in northeast Asia have focused on $\mathrm{SPOH}$, an indicator of RA, and the comprehensive oral health status of an individual. Therefore, this study aimed to identify a potential relationship between $\mathrm{RA}$ and oral health by identifying $\mathrm{SPOH}$ in Korean adults using representative national data from the Korea National Health and Nutrition Examination Survey (KNHANES).

\section{Methods}

\subsection{Study Design and Data Collection}

2.1.1. Study Design

Our study used data from KNHANES, which is a series of cross-sectional, nationally representative, population-based surveys on the health and nutritional status of Korean citizens conducted by the Korea Centers for Disease Control and Prevention [23].

\subsubsection{Inclusion and Exclusion Criteria}

Our study collected data from a total of 97,622 people who were surveyed between 2007 and 2018, representative of the Korean population. After excluding individuals aged under 20 years $(n=23,041)$, those who did not have an oral examination or complete the questionnaire $(n=29,800)$, and those who had missing data or data we could not use for other variables $(n=4595)$ (Figure 1), 40,186 people were selected as participants of this study.

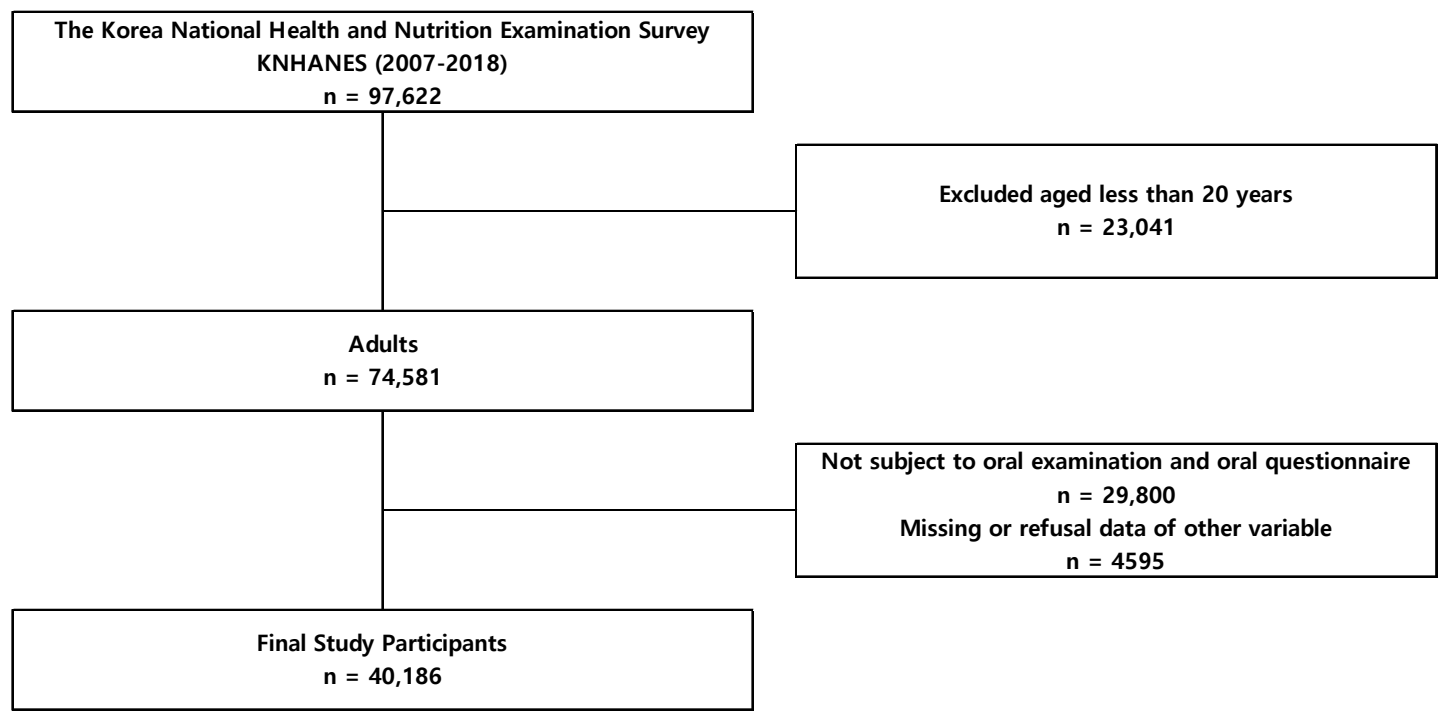

Figure 1. Schematic diagram of study participants.

\subsection{Study Variables}

\subsubsection{Exposure and Outcomes}

The KNHANES includes a health interview, health examination, and nutrition survey. The interviews and check-ups were conducted by trained staff, such as doctors, medical technicians, and health interviewers. 
As in previous studies, according to a self-administered questionnaire, "Have you been diagnosed with rheumatoid arthritis by a doctor?", participants who answered "yes" to the diagnosis of RA [16] in the KNHANES health survey were defined as the RA group; pseudo-diagnosis was defined as the non-RA group.

SPOH was measured on a 5-point Likert scale (very good, good, normal, bad, very bad) in response to an individual's perception of their oral health [24]. If a participant defined their oral health as "bad" or "very bad", this was indicative of poor oral health.

\subsubsection{Other Variables}

In this study, sex, age, income, and educational background were investigated in terms of demographic and social characteristics. Age was divided into four groups: 20-39 years, 40-59 years, 60-79 years, and 80 years of age or older. Income level was divided based on the median value, and the educational background of the participants was divided into two groups: high school or below and college or above.

According to previous studies, the prevalence of diabetes in patients with RA is high [25] and is also a primary risk factor for PD [26]; this makes diabetes a health status variable. This study was conducted on adults over the age of 20 , and the diabetes model was viewed as common type 2 diabetes.

According to a study on oral health and disease activity in RA patients [27], RA patients who smoke had dry mouth, gingival bleeding, and difficulty chewing. Smoking is an important factor that negatively affects oral health [28] and is related to PD development in patients with RA [14,29]. Smoking experiences are divided into three groups according to the self-administered questionnaires: (i) Non-smokers mean those who have never smoked; (ii) ex-smokers mean those who smoked in the past but not currently; (iii) smokers mean those who currently smoke. In this study, non-smokers and ex-smokers were classified as "no" and current smokers were classified as "yes". To determine oral health behavior, participants were asked how frequently they brushed their teeth each day. As in previous studies, responses were divided into $\geq 3$ times a day and $<3$ times a day [30]. Participants were also asked whether they had attended an oral examination within the past year. Responses were divided into "yes" or "no".

\subsection{Statistical Analysis}

Analysis of the data obtained from this cross-sectional study from the KNHANES (2007-2018) was conducted to identify an association between RA status and SPOH. For the general characteristics of the study subjects, frequency analysis, and descriptive statistics were conducted according to whether the participants had poor oral health. To obtain the risk ratio of the dependent variable according to the independent variable, the prevalence relative risk (PRR) was estimated using Poisson regression analysis [31]. In general, in cross-sectional studies, even if the prevalence odds ratio (OR) is obtained through logistic regression analysis, it is widely used to approximate the risk of prevalence comparison. However, the prevalence of focal health is not rare, therefore the risk of prevalence was calculated through Poisson analysis. To select an adjusted variable, a directed acyclic graph (DAG) was used [32] (Figure S1). Although it is known that RA may affect diabetes mellitus (DM) [33], some reports show that DM affects RA [34]; therefore, an additional DAG was implemented (Figure S2). As a result, sex, age, smoking, and DM were included as adjusted variables. Therefore, Model 2 defined sex, age, and smoking as adjusted variables, and Model 3 defined sex, age, smoking, and DM as adjusted variables. A complete denture may be observed as an outlier that is different from the general oral environment; therefore, sensitivity analysis was also performed, excluding individuals who had a complete denture. Data were analyzed using the SAS 9.4 software package (SAS Institute Inc., Cary, NC, USA).

\section{Results}

Table 1 lists the characteristics of the study participants according to whether they had poor oral health. RA was significantly higher in the group with poor oral health (52.6\%, 
$p<0.0001)$. This group consisted mostly of men $(44.9 \%, p<0.0001)$, the elderly $(51.6 \%, p$ $<0.0001)$, individuals with a low-income $(49.4 \%, p<0.0001)$ and a low level of education (47.6\%, $p<0.0001)$, smokers (53.4\%, $p<0.0001)$, individuals with DM $(54.2 \%, p<0.0001)$, and those who did not brush their teeth regularly $(47.5 \%, p<0.0001)$ and who did not have an oral examination within the last year $(45.3 \%, p<0.0001)$.

Table 1. Characteristics of participants according to poor oral health.

\begin{tabular}{|c|c|c|c|}
\hline \multicolumn{4}{|c|}{ Poor Oral Health } \\
\hline & No & Yes & $p$-Value \\
\hline Total & $22,687(56.5)$ & $17,499(43.6)$ & \\
\hline \multicolumn{4}{|l|}{ Sex } \\
\hline Men & $9553(55.1)$ & $7787(44.9)$ & $<0.0001$ \\
\hline Women & $13,134(57.5)$ & $9712(42.5)$ & \\
\hline \multicolumn{4}{|l|}{ Age } \\
\hline 20-39 & 7459 (64.5) & 4115 (35.6) & $<0.0001$ \\
\hline $40-59$ & $8879(57.1)$ & $6681(42.9)$ & \\
\hline $60-79$ & $5888(48.7)$ & $6212(51.3)$ & \\
\hline$\geq 80$ & $461(48.4)$ & $491(51.6)$ & \\
\hline \multicolumn{4}{|l|}{ House Income } \\
\hline Low & $8846(50.6)$ & $8621(49.4)$ & $<0.0001$ \\
\hline High & $13,841(60.9)$ & $8878(39.1)$ & \\
\hline \multicolumn{4}{|l|}{ Education } \\
\hline $\begin{array}{l}\text { High school or } \\
\text { below }\end{array}$ & $15,151(52.4)$ & $13,745(47.6)$ & $<0.0001$ \\
\hline College or above & $7536(66.8)$ & $3754(33.3)$ & \\
\hline \multicolumn{4}{|l|}{ Smoking } \\
\hline Non-/ex-smoker & $19,144(58.8)$ & $13,442(41.3)$ & $<0.0001$ \\
\hline Current smoker & $3543(46.6)$ & $4057(53.4)$ & \\
\hline \multicolumn{4}{|l|}{ Diabetes mellitus } \\
\hline No & $20,585(57.8)$ & $15,008(42.2)$ & $<0.0001$ \\
\hline Yes & $2102(45.8)$ & $2491(54.2)$ & \\
\hline \multicolumn{4}{|l|}{ Tooth brushing } \\
\hline$<3$ & $11,031(52.5)$ & 9967 (47.5) & $<0.0001$ \\
\hline$\geq 3$ & $11,656(60.8)$ & $7532(39.3)$ & \\
\hline \multicolumn{4}{|l|}{$\begin{array}{l}\text { Oral examination } \\
\text { within } 1 \text { year }\end{array}$} \\
\hline No & $15,433(54.7)$ & $12,800(45.3)$ & $<0.0001$ \\
\hline Yes & 7254 (60.7) & 4699 (39.3) & \\
\hline \multicolumn{4}{|l|}{$\mathrm{RA}^{*}$} \\
\hline No & $22,311(56.6)$ & $17,081(43.4)$ & $<0.0001$ \\
\hline Yes & $376(47.4)$ & 418 (52.6) & \\
\hline
\end{tabular}

* Rheumatoid arthritis.

In this study, the number of women $(80.1 \%, p<0.0001)$, elderly $(56.3 \%, p<0.0001)$, individuals with lower income $(57.7 \%, p<0.0001)$ and education levels $(87.9 \%, p<0.0001)$, non-smokers $(90.6 \%, p<0.0001)$, individuals without DM $(84.0 \%, p<0.0001)$, and those who brushed their teeth less frequently $(57.2 \%, p=0.005)$ and did not attend an oral examination within the last year $(75.9 \%, p=0.0004)$ was higher in the RA group when compared to the non-RA group (Table S1).

As shown in Table 2, the crude OR of SPOH for RA in Model 1, considering the non-RA group as reference, was 1.214 (95\% confidence interval [CI] 1.102-1.338). In Model 2, the OR for the RA group was 1.108 (95\% CI 1.005-1.222), and the OR in Model 3 for the RA groups was 1.108 (95\% CI: 1.005-1.222). All the age groups analyzed showed an increase in risk: 20-39 years $(\mathrm{OR}=1.047,95 \%$ CI 0.695-1.578), 40-59 years $(\mathrm{OR}=1.211,95 \% \mathrm{CI} 1.015-1.443)$, and $60-79(\mathrm{OR}=1.109,95 \% \mathrm{CI} 0.977-1.258)$; however, the risk decreased in the over 80 years group $(\mathrm{OR}=0.871,95 \% \mathrm{CI} 0.52-1.457)$. The group with $\mathrm{DM}$ showed a higher risk than the group without DM $(\mathrm{OR}=1.205,95 \% \mathrm{CI} 0.966-1.503)$. When sex, income, educational background, smoking, frequency of toothbrushing and oral examinations attended were 
stratified, most of the ORs did not show any considerable difference after the adjustment. These results are similar to those of the sensitivity analysis (Table S2).

Table 2. Odds ratios of self-perceived oral health according to rheumatoid arthritis.

\begin{tabular}{|c|c|c|c|}
\hline & Model1 ${ }^{\dagger}$ & Model2 $\ddagger$ & Model3 $\S$ \\
\hline Total & $1.214(1.102-1.338)$ & 1.108 (1.005-1.222) & 1.108 (1.005-1.222) \\
\hline \multicolumn{4}{|l|}{ Sex } \\
\hline Men & $1.229(0.995-1.518)$ & $1.146(0.928-1.416)^{\mathrm{a}}$ & $1.147(0.928-1.418)^{b}$ \\
\hline Women & $1.232(1.104-1.375)$ & $1.1(0.985-1.229)^{\mathrm{a}}$ & $1.1(0.985-1.228)^{b}$ \\
\hline \multicolumn{4}{|l|}{ Age } \\
\hline $20-39$ & $1.044(0.693-1.572)$ & $1.047(0.695-1.577)$ & $1.047(0.695-1.578)$ \\
\hline $40-59$ & 1.177 (0.988-1.403) & $1.208(1.013-1.44)$ & $1.211(1.015-1.443)$ \\
\hline $60-79$ & $1.107(0.976-1.255)$ & $1.11(0.978-1.26)$ & 1.109 (0.977-1.258) \\
\hline$\geq 80$ & $0.878(0.525-1.467)$ & $0.865(0.517-1.447)$ & $0.871(0.52-1.457)$ \\
\hline \multicolumn{4}{|l|}{ House income } \\
\hline Low & $1.132(0.999-1.282)$ & $1.075(0.948-1.218)$ & $1.073(0.946-1.216)$ \\
\hline High & $1.246(1.067-1.455)$ & $1.155(0.988-1.35)$ & $1.161(0.993-1.356)$ \\
\hline \multicolumn{4}{|l|}{ Education } \\
\hline $\begin{array}{l}\text { High school or } \\
\text { below }\end{array}$ & $1.161(1.049-1.285)$ & $1.113(1.005-1.232)$ & $1.112(1.004-1.232)$ \\
\hline College or above & $1.066(0.76-1.494)$ & 1.009 (0.719-1.415) & $1.013(0.722-1.42)$ \\
\hline \multicolumn{4}{|l|}{ Smoking } \\
\hline No & $1.258(1.135-1.395)$ & $1.113(1.003-1.235)^{\mathrm{C}}$ & $1.113(1.003-1.234)^{\mathrm{d}}$ \\
\hline Yes & $1.176(0.882-1.568)$ & $1.053(0.789-1.406)^{\mathrm{c}}$ & $1.053(0.789-1.406)^{\mathrm{d}}$ \\
\hline \multicolumn{4}{|l|}{ Diabetes mellitus } \\
\hline No & $1.196(1.073-1.332)$ & $1.088(0.976-1.214)$ & - \\
\hline Yes & $1.212(0.974-1.509)$ & $1.205(0.966-1.503)$ & - \\
\hline \multicolumn{4}{|l|}{ Tooth brushing } \\
\hline$<3$ & $1.169(1.031-1.325)$ & $1.112(0.98-1.262)$ & $1.109(0.978-1.259)$ \\
\hline$\geq 3$ & 1.257 (1.078-1.465) & 1.099 (0.941-1.282) & $1.103(0.945-1.287)$ \\
\hline \multicolumn{4}{|l|}{$\begin{array}{l}\text { Oral examination } \\
\text { within } 1 \text { year }\end{array}$} \\
\hline No & $1.213(1.087-1.353)$ & $1.108(0.992-1.237)$ & 1.107 (0.991-1.236) \\
\hline Yes & 1.175 (0.952-1.451) & $1.089(0.881-1.347)$ & $1.094(0.885-1.352)$ \\
\hline
\end{tabular}

${ }^{\dagger}$ Crude odds ratio was calculated by Poisson analysis; ${ }^{\ddagger}$ Adjusted odds ratio was calculated by Poisson analysis after adjusting for sex, age, and smoking; ${ }^{\S}$ Adjusted odds ratio was calculated by Poisson analysis after adjusting for sex, age, smoking, and diabetes mellitus; ${ }^{a}$ Adjusted for age, smoking; ${ }^{b}$ Adjusted for age, smoking, and diabetes mellitus; ${ }^{\mathrm{c}}$ Adjusted for sex, age; ${ }^{\mathrm{d}}$ Adjusted for sex, age, and diabetes mellitus.

\section{Discussion}

In this study, we identified an association between RA and $\mathrm{SPOH}$. Previous studies have shown that patients with RA have fewer teeth [12], a higher reported risk of PD than the general population [14-16], and have a poor oral health quality of life [17-19] when compared to individuals without RA. The observations from these studies support the results from our current study.

RA is an autoimmune disease characterized by an accumulation of inflammatory cells that occurs due to changes in the systemic immune function. RA destroys cartilage and joint bone tissue and causes physical disabilities [35] as well as pain, swelling, and disability in TMJ [21,22]. RA and PD have a common biomedical mechanism [36] of bone destruction caused by inflammatory cytokines [35,37].

In general, patients with RA may have a reduced ability to perform oral hygiene due to the limited movement of the wrist and finger joints [35,38], thereby increasing inflammatory activity and the risk of developing PD. In addition, RA patients often had oral pain or discomfort due to poor periodontal conditions and had difficulty brushing their teeth [20]; gingival bleeding also occurred while brushing teeth and was frequently diagnosed with periodontitis [39]. If brushing teeth is difficult due to joint motion restrictions, it is recommended to improve oral hygiene by the use of electric toothbrushes [40]. 
Subgroup analysis stratified by age and diabetes status highlighted differences in the association between RA and oral health. There was an association between poor oral health and RA in the diabetic group. This observation was consistent with previous studies that reported poor oral health due to tooth decay or PD in adults with diabetes [41]. Therefore, the risk of poor oral health in RA patients with diabetes is increased. Subgroup analysis of those aged 80 years or older revealed a non-significant association between oral health and RA. The accumulated oral health status of the elderly is affected by various diseases. Previous studies report multiple tooth losses [42] and the development of systemic diseases in elderly patients [43]. This might explain the lack of association between RA and oral health in the elderly. Previous studies showed interactions in sex [44,45], smoking [27], and frequency of toothbrushing [18] stratification, but in this study, there was no considerable difference even after adjustment in the stratified subgroup analysis.

This study had several strengths. First, the number of samples used for analysis was sufficient and represented the entire nation. Second, to our knowledge, there has been no study in northeast Asia that can show a comprehensive oral health status using $\mathrm{SPOH}$ variables. This study is the first in northeast Asia to use $\mathrm{SPOH}$, an index that comprehensively shows the oral health status of RA patients, for analysis.

This study has some limitations. First, it was difficult to reveal a causal relationship because the National Health and Nutrition Survey is cross-sectional. The cross-sectional data showed that the duration of the disease could not be defined and the diabetes model was considered a general type 2 diabetes, considering that it was an adult over the age of 20, so we think it would be difficult to represent the entire diabetes group. To prove a causal relationship, it is necessary to conduct a longitudinal study in the future. Second, correction variable data that were missing from the database remain unknown and could not be corrected. Despite these limitations, this study is valuable as it examines data from previous studies using the DAG method, includes them as adjusted variables, and analyzes them using representative national data.

We would like to make some suggestions for further research. First, we should find major causes such as demographic factors, health statuses like diabetes, and oral health behavior that threaten the oral health of RA patients and propose active information exchange and cooperation between rheumatologists and dentists to acquire the correct oral health status of RA patients. Second, we think preventive activities are necessary to achieve satisfactory oral health by inducing regular oral examinations of RA patients and developing oral care programs considerate of age.

\section{Conclusions}

In the presence of RA, poor oral health was statistically significant. There was an increase in the risk of poor oral health in the entire group with RA, especially in the diabetic group. Oral health experts should identify the factors affecting the oral health of patients with RA and provide correct oral health care; however, additional research is needed.

Supplementary Materials: The following are available online at https: / www.mdpi.com/article/ 10.3390/healthcare10030427/s1, Table S1: Characteristics of participants according to rheumatoid arthritis status, Table S2: Odds ratios of self-perceived oral health according to rheumatoid arthritis excluding the person with the complete dentures, Figure S1: Directed acyclic graphs for variable selection, Figure S2: Directed acyclic graphs for variable selection.

Author Contributions: Conceptualization and methodology, H.S., J.K. and J.A.; Data collection: H.S. and J.A.; data analysis: J.A.; manuscript writing: H.S. and J.A. supervision, J.K. All authors have read and agreed to the published version of the manuscript.

Funding: This research received no external funding.

Institutional Review Board Statement: Our study was exempted from deliberation by the Institutional Review Board of Seoul St. Mary's Hospital, the Catholic University of Korea (study number: MC21ZISI0109). 
Informed Consent Statement: Informed consent was obtained from all participants involved in the KNHANES by KCDC.

Data Availability Statement: Not applicable.

Conflicts of Interest: The authors declare no conflict of interest.

\section{References}

1. Wu, S.; Wang, R.; Zhao, Y.; Ma, X.; Wu, M.; Yan, X.; He, J. The relationship between self-rated health and objective health status: A population-based study. BMC Public Health 2013, 13, 320. [CrossRef] [PubMed]

2. Kim, Y.; Jang, E. Low Self-Rated Health as A Risk Factor for Depression in South Korea: A Survey of Young Males and Females. Healthcare 2021, 9, 452. [CrossRef]

3. DeSalvo, K.B.; Fan, V.S.; McDonell, M.B.; Fihn, S.D. Predicting mortality and healthcare utilization with a single question. Health Serv. Res. 2005, 40, 1234-1246. [CrossRef] [PubMed]

4. Adunola, F.; Garcia, I.; Iafolla, T.; Boroumand, S.; Silveira, M.L.; Adesanya, M.; Dye, B.A. Self-perceived oral health, normative need, and dental services utilization among dentate adults in the United States: National Health and Nutrition Examination Survey (NHANES) 2011-2014. J. Public Health Dent. 2019, 79, 79-90. [CrossRef] [PubMed]

5. Fiorillo, L. Oral Health: The First Step to Well-Being. Medicina 2019, 55, 676. [CrossRef]

6. Petersen, P.E. Global policy for improvement of oral health in the 21st century-implications to oral health research of World Health Assembly 2007, World Health Organization. Community Dent. Oral Epidemiol. 2009, 37, 1-8. [CrossRef]

7. Glick, M.; Williams, D.M.; Kleinman, D.V.; Vujicic, M.; Watt, R.G.; Weyant, R.J. A new definition for oral health developed by the FDI World Dental Federation opens the door to a universal definition of oral health. Br. Dent. J. 2016, 221, 792-793. [CrossRef]

8. McGrath, C. Behavioral Sciences in the Promotion of Oral Health. J. Dent. Res. 2019, 98, 1418-1424. [CrossRef]

9. Abdul-Sattar, A.B.; Goda, T.; Negm, M.G. Neuropsychiatric manifestations in a consecutive cohort of systemic lupus erythematosus; a single center study. Int. J. Rheum. Dis. 2013, 16, 715-723. [CrossRef]

10. Routsias, J.G.; Goules, J.D.; Goules, A.; Charalampakis, G.; Pikazis, D. Autopathogenic correlation of periodontitis and rheumatoid arthritis. Rheumatology 2011, 50, 1189-1193. [CrossRef]

11. Mercado, F.; Marshall, R.I.; Klestov, A.C.; Bartold, P.M. Is there a relationship between rheumatoid arthritis and periodontal disease? J. Clin. Periodontol. 2000, 27, 267-272. [CrossRef] [PubMed]

12. Lagervall, M.; Jansson, L.; Bergström, J. Systemic disorders in patients with periodontal disease. J. Clin. Periodontol. 2003, 30, 293-299. [CrossRef] [PubMed]

13. Martinez-Martinez, R.E.; Abud-Mendoza, C.; Patiño-Marin, N.; Rizo-Rodríguez, J.C.; Little, J.W.; Loyola-Rodríguez, J.P. Detection of periodontal bacterial DNA in serum and synovial fluid in refractory rheumatoid arthritis patients. J. Clin. Periodontol. 2009, 36, 1004-1010. [CrossRef] [PubMed]

14. Detert, J.; Pischon, N.; Burmester, G.R.; Buttgereit, F. The association between rheumatoid arthritis and periodontal disease. Arthritis Res. Ther. 2010, 12, 218. [CrossRef]

15. De Pablo, P.; Dietrich, T.; McAlindon, T.E. Association of periodontal disease and tooth loss with rheumatoid arthritis in the US population. J. Rheumatol. 2008, 35, 70-76.

16. Jung, E.S.; Choi, Y.Y.; Lee, K.H. Relationship between rheumatoid arthritis and periodontal disease in Korean adults: Data from the Sixth Korea National Health and Nutrition Examination Survey, 2013 to 2015. J. Periodontol. 2019, 90, 350-357. [CrossRef]

17. Tristiu, R.; Vesa, S.; Dumitru, R.B.; Arweiler, N.B.; Cosgarea, R.M.; Lascu, L.; Rednic, S.; Eick, S.; Sculean, A.; Cosgarea, R. Association of Oral-Health Related Quality of Life and General Health Assessment in Patients with Rheumatoid Arthritis. Oral Health Prev. Dent. 2018, 16, 271-280. [CrossRef]

18. de Azevedo Branco, L.G.; Oliveira, S.R.; Corrêa, J.D.; Calderaro, D.C.; Mendonça, S.M.S.; de Queiroz Cunha, F.; Ferreira, G.A.; Teixeira, A.L.; Abreu, L.G.; Silva, T.A. Oral health-related quality of life among individuals with rheumatoid arthritis. Clin. Rheumatol. 2019, 38, 2433-2441. [CrossRef]

19. Schmalz, G.; Patschan, S.; Patschan, D.; Ziebolz, D. Oral-Health-Related Quality of Life in Adult Patients with Rheumatic Diseases-A Systematic Review. J. Clin. Med. 2020, 9, 1172. [CrossRef]

20. Radwan-Oczko, M.; Duś-Ilnicka, I.; Richards, P.; Thomsen, A.M.; Rasmussen, C. Evaluation of Oral Health Status and Oral Care of Patients with Rheumatoid Arthritis. Int. J. Dent. 2020, 2020, 8896766. [CrossRef]

21. González-Chávez, S.A.; Pacheco-Tena, C.; de Jesús Caraveo-Frescas, T.; Quiñonez-Flores, C.M.; Reyes-Cordero, G.; Campos-Torres, R.M. Oral health and orofacial function in patients with rheumatoid arthritis. Rheumatol. Int. 2020, 40, 445-453. [CrossRef]

22. Kroese, J.M.; Kopp, S.; Lobbezoo, F.; Alstergren, P. TMJ Pain and Crepitus Occur Early Whereas Dysfunction Develops Over Time in Rheumatoid Arthritis. J. Oral Facial Pain Headache 2020, 34, 398-405. [CrossRef] [PubMed]

23. Kweon, S.; Kim, Y.; Jang, M.J.; Kim, Y.; Kim, K.; Choi, S.; Chun, C.; Khang, Y.H.; Oh, K. Data resource profile: The Korea National Health and Nutrition Examination Survey (KNHANES). Int. J. Epidemiol. 2014, 43, 69-77. [CrossRef] [PubMed]

24. Atchison, K.A.; Gift, H.C. Perceived oral health in a diverse sample. Adv. Dent. Res. 1997, 11, 272-280. [CrossRef] [PubMed]

25. Tian, Z.; McLaughlin, J.; Verma, A.; Chinoy, H.; Heald, A.H. The relationship between rheumatoid arthritis and diabetes mellitus: A systematic review and meta-analysis. Cardiovasc. Endocrinol. Metab. 2021, 10, 125-131. [CrossRef] [PubMed] 
26. Preshaw, P.M.; Bissett, S.M. Periodontitis: Oral complication of diabetes. Endocrinol. Metab. Clin. N. Am. 2013, 42, 849-867. [CrossRef] [PubMed]

27. Radwan-Oczko, M.; Duś-Ilnicka, I.; Richards, P.; Thomsen, A.M.; Rasmussen, C. Rheumatoid arthritis patients' oral health and disease activity. Int. J. Rheum. Dis. 2019, 22, 1538-1543. [CrossRef]

28. Vettore, M.V.; Faerstein, E.; Baker, S.R. Social position, social ties and adult's oral health: 13 year cohort study. J. Dent. 2016, 44, 50-56. [CrossRef]

29. Stolt, P.; Bengtsson, C.; Nordmark, B.; Lindblad, S.; Lundberg, I.; Klareskog, L.; Alfredsson, L.; EIRA study group. Quantification of the influence of cigarette smoking on rheumatoid arthritis: Results from a population based case-control study, using incident cases. Ann. Rheum. Dis. 2003, 62, 835-841. [CrossRef]

30. Kim, D.W.; Park, J.C.; Rim, T.T.; Jung, U.W.; Kim, C.S.; Donos, N.; Cha, I.H.; Choi, S.H. Socioeconomic disparities of periodontitis in Koreans based on the KNHANES IV. Oral Dis. 2014, 20, 551-559. [CrossRef]

31. Zou, G. A modified poisson regression approach to prospective studies with binary data. Am. J. Epidemiol. 2004, 159, 702-706. [CrossRef] [PubMed]

32. Textor, J.; Hardt, J.; Knüppel, S. DAGitty: A graphical tool for analyzing causal diagrams. Epidemiology 2011, 22, 745. [CrossRef] [PubMed]

33. Jiang, P.; Li, H.; Li, X. Diabetes mellitus risk factors in rheumatoid arthritis: A systematic review and meta-analysis. Clin. Exp. Rheumatol. 2015, 33, 115-121. [PubMed]

34. Boyer, J.F.; Gourraud, P.A.; Cantagrel, A.; Davignon, J.L.; Constantin, A. Traditional cardiovascular risk factors in rheumatoid arthritis: A meta-analysis. Joint Bone Spine 2011, 78, 179-183. [CrossRef] [PubMed]

35. Pischon, N.; Pischon, T.; Kröger, J.; Gülmez, E.; Kleber, B.-M.; Bernimoulin, J.-P.; Landau, H.; Brinkmann, P.-G.; Schlattmann, P.; Zernicke, J.; et al. Association among rheumatoid arthritis, oral hygiene, and periodontitis. J. Periodontol. 2008, 79, 979-986. [CrossRef] [PubMed]

36. Kobayashi, T.; Murasawa, A.; Komatsu, Y.; Yokoyama, T.; Ishida, K.; Abe, A.; Yamamoto, K.; Yoshie, H. Serum cytokine and periodontal profiles in relation to disease activity of rheumatoid arthritis in Japanese adults. J. Periodontol. 2010, 81, 650-657. [CrossRef] [PubMed]

37. Ishi, E.P.; Bertolo, M.B.; Rossa, C., Jr.; Kirkwood, K.L.; Onofre, M.A. Periodontal condition in patients with rheumatoid arthritis. Braz. Oral Res. 2008, 22, 72-77. [CrossRef]

38. Mühlberg, S.; Jäger, J.; Krohn-Grimberghe, B.; Patschan, S.; Mausberg, R.F.; Schmalz, G.; Haak, R.; Ziebolz, D. Oral health-related quality of life depending on oral health in patients with rheumatoid arthritis. Clin. Oral Investig. 2017, 21, 2661-2670. [CrossRef]

39. Furuya, T.; Inoue, E.; Tanaka, E.; Maeda, S.; Ikari, K.; Taniguchi, A.; Yamanaka, H. Age and female gender associated with periodontal disease in Japanese patients with rheumatoid arthritis: Results from self-reported questionnaires from the IORRA cohort study. Mod. Rheumatol. 2020, 30, 465-470. [CrossRef]

40. Bahammam, S.; Chen, C.Y.; Ishida, Y.; Hayashi, A.; Ikeda, Y.; Ishii, H.; Kim, D.M.; Nagai, S. Electric and Manual Oral Hygiene Routines Affect Plaque Index Score Differently. Int. J. Environ. Res. Public Health 2021, 18, 13123. [CrossRef]

41. Huang, D.L.; Chan, K.C.G.; Young, B.A. Poor oral health and quality of life in older U.S. adults with diabetes mellitus. J. Am. Geriatr. Soc. 2013, 61, 1782-1788. [CrossRef] [PubMed]

42. Hassel, A.J.; Safaltin, V.; Grill, S.; Schröder, J.; Wahl, H.W.; Klotz, A.L.; Habibi, E.; Rammelsberg, P.; Zenthöfer, A. Risk factors for tooth loss in middle and older age after up to 10 years: An observational cohort study. Arch. Oral Biol. 2018, 86, 7-12. [CrossRef]

43. Persson, G.R. Periodontal complications with age. Periodontol. 2000 2018, 78, 185-194. [CrossRef] [PubMed]

44. Ahmed, S.; Kumar, S.; Alsaadi, R.A.; Ansari, F.M.; Abrol, S.; Bhowmick, D.; Tabassum, N. Oral Health and Rheumatoid Arthritis: A Case Control Study. J. Pharm. Bioallied Sci. 2021, 13, S315-S318. [CrossRef] [PubMed]

45. Iikuni, N.; Sato, E.; Hoshi, M.; Inoue, E.; Taniguchi, A.; Hara, M.; Tomatsu, T.; Kamatani, N.; Yamanaka, H. The influence of sex on patients with rheumatoid arthritis in a large observational cohort. J. Rheumatol. 2009, 36, 508-511. [CrossRef] 